\title{
Immunological evidence for the co-existence of the Lambert-Eaton myasthenic syndrome and myasthenia gravis in two patients
}

\author{
J Newsom-Davis, K Leys, A Vincent, I Ferguson, G Modi, K Mills
}

\begin{abstract}
Two patients are described in whom a clinical and electromyographic diagnosis of the Lambert-Eaton myasthenic syndrome (LEMS) was made. Serum antibodies to voltage-gated calcium channels (VGCCs), the antigenic target in LEMS and to acetylcholine receptors (AChRs), the antigen in myasthenia gravis, were detected at raised titres in both cases, using radioimmunoassays based on ${ }^{125} I-\omega$-Conotoxin labelled VGCCs and ${ }^{125} I-\alpha$-Bungarotoxin labelled AChRs. These data provide immunological evidence for the coexistence of the two disorders in these patients.
\end{abstract}

Myasthenia gravis (MG) and the LambertEaton myasthenic syndrome (LEMS) are both antibody-mediated autoimmune disorders of neuromuscular transmission. The antigenic targets are the postsynaptic acetylcholine receptors (AChRs) and the presynaptic voltage-gated calcium channels (VGCCs) respectively ${ }^{1}$ Combined MG and LEMS have been reported in occasional patients, as recently reviewed. ${ }^{2}$ The diagnosis in these cases has depended on clinical and electromyographic criteria or, in more recent studies, on the presence also of the specific antibody in MG, anti-AChR antibody. A radioimmunoassay for the detection of anti-VGCC antibodies is now available in which the antigen (VGCC) is labelled with the marine snail toxin $\omega$-conotoxin $(\omega-\mathrm{CgTx}) .^{3-5}$ We report here two patients with myasthenic weakness diagnosed as LEMS in whose sera anti-AChR as well as anti-VGCC IgG autoantibodies were detected.

\section{Methods}

Anti-AChR antibodies were detected by a radioimmunoassay (RIA) as previously described, ${ }^{6}$ using ${ }^{125} \mathrm{I}-\alpha$-BuTx labelled human muscle AChR obtained from amputees.

Anti-VGCC antibodies were detected by an RIA using ${ }^{125} \mathrm{I}-\omega-\mathrm{CgTx}$ labelled VGCCs as antigen. VGCCs were extracted from prelabelled membranes prepared from cultured cells of the human neuroblastoma line SKNSH, as previously described. ${ }^{7}$

\section{Case reports}

Case 1

At the age of 59 , this white male first complained of a dry mouth and reduced sexual potency. He was investigated for back and abdominal pains in 1984 and at that time had difficulty in raising his arms and in rising from a chair without using his arms. There was a past history of epilepsy for which he received phenytoin and phenobarbitone. His erythrocyte sedimentation rate was raised $(68 \mathrm{~mm} /$ hour) and, following a presumptive diagnosis of polymyalgia rheumatica, he received a short course of daily prednisone and improved.

In November 1987, aged 67, he was readmitted with a two month history of increasing weakness of limb, respiratory, facial and bulbar muscles including difficulty with chewing. He required intubation and assisted ventilation. Tendon reflexes were absent. An edrophonium test was positive and electromyography showed a reduced amplitude of the compound muscle action potential (CMAP) in the abductor pollicis brevis $(4.4 \mathrm{mV}$; normal $>8.4$ ), increasing to $9.9 \mathrm{mV}$ (increment $125 \%$ ) after $30 \mathrm{~Hz}$ stimulation. A CT chest scan and bronchoscopy showed no evidence of malignancy; he had been a non-smoker for 15 years.

A diagnosis of LEMS was made and treatment was started with prednisolone, azathioprine, pyridostigmine, and 3,4-Diaminopyridine together with a course of plasmapheresis. Strength steadily improved. In January 1988, serum was tested for anti-AChR antibodies, and was strongly positive $(169 \times$ $10^{-10} \mathrm{M}$; normal $<2$ ). Improvement continued and by December 1989, when taking prednisolone $30 \mathrm{mg}$ on alternate days and azathioprine $150 \mathrm{mg}$ daily, he could walk half a mile although still aware of variable strength in his arms and of a dry mouth. Electromyography showed increased jitter in the right extensor digitorum communis (mean $114 \mu \mathrm{s}, \mathrm{n}=11$ pairs; normal $<53 \mu \mathrm{s}$ ), confirming a disorder of neuromuscular transmission. The CMAP amplitude in the right abductor pollicis brevis was now $11.1 \mathrm{mV}$, increasing to $14.5 \mathrm{mV}$ after 15 seconds MVC, an increment of $30 \%$ (normal <25\%). The anti-AChR titre (19 December 1989) was $124 \times 10^{-10} \mathrm{M}$ and the anti-VGCC titre $45 \mathrm{pM}$ (normal <30). The 
serum sample originally assayed for antiAChR antibody in another laboratory on 29 January 1988 was no longer available for study.

Case 2

This 31 year old black South African female complained of proximal limb weakness and fatiguability of six months duration when seen in March 1990. Weakness increased following exercise and fluctuated during the day. She had not experienced ocular or autonomic symptoms. She was a non-smoker.

Examination showed mild bilateral face and neck weakness and moderate proximal weakness of the upper and lower limbs; fatiguability was easily demonstrable. Her tendon reflexes were absent but could be elicited after maximum voluntary contraction of the muscle (post-tetanic potentiation). A clinical diagnosis of LEMS was made.

Electromyography showed a reduced CMAP amplitude in the abductor digiti minimi $(3.9 \mathrm{mV})$, and a $35 \%$ increase following stimulation at $20 \mathrm{~Hz}$. A chest radiograph was normal and bronchial brushings with cytology were negative for malignant cells. Serum electrophoresis was normal and antinuclear factor was not detected.

A serum sample tested on 6 March 1990 for anti-AChR antibodies and for anti-VGCC antibodies showed titres of $317 \times 10^{-10} \mathrm{M}$ and $100 \mathrm{pM}$ respectively.

\section{Discussion}

In both these cases, the initial clinical diagnosis was LEMS, based on the typical findings of proximal muscle weakness and absent reflexes that showed post-tetanic potentiation in case 2 . In case 1 autonomic changes that commonly occur in LEMS $^{8}$ were the presenting features. In both cases the amplitude of the CMAP in a small muscle of the hand was reduced, and showed an increment during repetitive stimulation that was above the normal upper limit. Possible clinical evidence for the coexistence of MG in case 1 was the striking bulbar weakness that included difficulty in chewing, a symptom not usually encountered in LEMS ${ }^{8}$ but typical of MG. In case 2 , there were no clinical features that could be attributed specifically to MG.

Both patients had high titres of anti-AChR antibodies. This antibody is specific for MG and is present in $85-90 \%$ of those with generalised disease. ${ }^{6}$ It can be detected at raised titre in MG patients in remission, and very occasionally in first degree relatives. ${ }^{6}$ In the two patients described here, and particularly in case 1 , it seems likely that the antibodies were contributing to the myasthenic weakness.

The radioimmunoassay for anti-VGCC antibodies has only recently been developed. Early reports indicate that antibodies can be detected in $44-80 \%$ of cases. ${ }^{3-5}$ This antibody may be present at raised titre (30-82 pM) in some patients with rheumatoid arthritis and systemic lupus erythematosus (SLE), but was not detected in patients with other neurological diseases. ${ }^{7}$ Neither of our patients had evidence of rheumatoid arthritis or SLE. The presence of these antibodies at raised titre in both these patients thus supports the clinical and electromyographic evidence for LEMS. In preliminary longitudinal studies there appears to be an inverse relationship between the antibody titre and muscle strength in some patients, ${ }^{7}$ as in MG. Thus in case 1 it is likely that the anti-VGCC titre was higher in November 1987 before immunosuppressive treatment was started, when his disorder was clinically at its most severe.

The occasional occurrence of LEMS and MG in the same patient might be expected since both show similar immune response gene associations..$^{10}$ This co-existence may be difficult to establish solely on clinical and electromyographic grounds. The availability of these two radioimmunoassays may prove helpful in resolving this diagnostic problem.

We are grateful to Mr Leslie Jacobson for help with the antiacetylcholine receptor antibody assay.

1 Newsom-Davis J. Autoimmunity in neuromuscular disease. Ann NY Acad Sci 1988;540:25-38.

2 Taphoorn MJB, Van Duijn H, Wolters ECH. A neuromuscular transmission disorder: combined myasthenia gravis and Lambert-Eaton syndrome in one patient. $J$ Neurol Neurosurg Psychiatry 1988;51:880-2.

3 Sher E, Gotti C, Canal N, Scoppetta C, Piccolo G, Evoli A Clementi F. Specificity of calcium channel autoantibodies in Lambert-Eaton myasthenic syndrome. Lancet 1989; ii: $640-3$.

4 Lennon VA, Lambert EH. Autoantibodies bind solubilized calcium channel $\omega$-Conotoxin complexes from small cell lung carcinoma: A diagnostic aid for Lambert-Eaton myasthenic syndrome. Mayo Clin Proc 1989;64:1498-504

5 Leys K, Lang B, Vincent A, Newsom-Davis:1498-504. channel autoantibodies in Lambert-Eaton myasthenic syndrome. Lancet 1989;ii:1107.

6 Vincent A, Newsom-Davis J. Acetylcholine receptor as a diagnostic test for myasthenia gravis: results in 153 diagnostic test for myasthenia gravis: results in 153 validated cases and 2967 diagnostic
Neurosurg Psychiatry 1985;48:1246-52.

7 Leys K, Lang B, Johnston I, Newsom-Davis J. Calcium channel autoantibodies in the Lambert-Eaton myasthenic syndrome. Ann Neurol (in press).

8 O'Neill JH, Murray NMF, Newsom-Davis J. The Lambert-Eaton myasthenic syndrome: a review of 50 cases. Brain 1988;111:577-96.

9 Willcox N, Demaine AG, Newsom-Davis J, Welsh KI, Robb SA, Spiro AG. Increased frequency of IgG heavy chain marker $(\mathrm{Glm}(2))$ and of HLA-B8 in Lambert-Eaton myasthenic syndrome with and without associated lun carcinoma. Human Immunology 1985;14:29-36.

10 Compston DAS, Vincent A, Newsom-Davis J, Batchelor JR. Clinical, pathological, HLA antigen and immunological evidence for disease heterogenity in myasthenia gravis. Brain 1980;103:579-601. 